\title{
Summation of responding to CSs and an excitatory test context
}

\author{
RALPH R. MILLER, NICHOLAS J. GRAHAME, and STEVE C. HALLAM \\ State University of New York, Binghamton, New York
}

The influence of test-trial delay of CS onset in obtaining response summation of an excitatory $\mathrm{CS}$ and an independently conditioned context was investigated. Water-deprived rats were given tone-shock and click-shock pairings in the training context and unsignaled footshocks in the test context. Durations of lick suppression in response to the tone (Test 1) and the click (Test 2) were then assessed in the test context. Licking was more suppressed when CS onset occurred early in the test session (e.g., 0 sec) than when it occurred later in the test session (e.g., 300 sec). The results from control groups that had received shock in an irrelevant context rather than the test context indicated that this effect was due to fear of the test context rather than diffuse, nonassociative fear. With onset of the clicks early in the test session on the second test day, response summation of the test context with the clicks was observed. This suggests that appreciable spontaneous recovery had occurred from any test-context extinction that took place on the first test day. We conclude that early onset of the CS on the test trial favors response summation of CSs and test context.

When two conditioned stimuli (CSs) that were previously independently paired with the same unconditioned stimulus (US) are presented in compound, conditioned responding is ordinarily greater than either the response to each element separately or the response to the compound if only one element had been conditioned (e.g., Grings, 1972; Weiss, 1972). Although both of these control procedures yield evidence of response summation, the latter is preferred because it avoids differences in generalization decrement that can mask part of the response-summation effect. The conventional explanation of summation of conditioned responding is associative summation of the underlying memories. ${ }^{1}$

Although response summation is commonly seen between two punctate CSs, there is some question about the circumstances under which response summation will be observed between a punctate CS and the context in which it is being tested. The present experiment is an attempt to establish boundary conditions for such response summation. Balaz, Capra, Kasprow, and Miller (1982) have demonstrated that prolonged exposure to a context prior to the presentation of the US in that context can interfere with the context's accruing an effective context-US association (i.e., latent inhibition of the context), thereby precluding the possibility of its subsequently summatively joining with a punctate $C S$ to enhance responding. In ad-

Support for this research was provided by National Science Foundation Grant BNS 86-00755 and National Institute of Mental Health Grant 33881. Thanks are due Mary Ann Balaz, Sharon Capra, and Phillipe Hartl for their assistance in conducting the research, and Louis D. Matzel and Susan L. Priore for their comments on an earlier version of the manuscript. Requests for reprints should be addressed to Ralph R. Miller, Department of Psychology, SUNY-Binghamton, Binghamton, NY 13901. dition, overt extinction of the context between conditioning of the test context and a summation test of the context with a punctate excitor is known to attenuate response summation (e.g., Balaz, Capra, Hartl, \& Miller, 1981). In both of these instances, the reduction of observed response summation presumably arose from the context having insufficient associative strength at the time of testing to contribute to conditioned responding. These studies suggest that summation will be evident when an excitatory CS is presented in an excitatory context, provided that ceiling effects are avoided.

However, even without overt latent inhibition treatment or overt extinction of the context, response summation of the context with a punctate CS has not been consistently observed. For example, Bouton and King (1986) failed to obtain response summation of a punctate excitatory CS and an excitatory context. There are several possible reasons for this discrepancy with the positive instances of summation such as the studies of Balaz et al. (1981, 1982). The present experiment was performed to illuminate one of these possibilities. Specifically, a notable difference between the two Balaz et al. studies and the Bouton and King experiments is that CS onset occurred at the very beginning of the test sessions in the Balaz et al. studies, but was delayed appreciably into the test session in Bouton and King's experiments.

\section{METHOD}

\footnotetext{
Subjects

Seventy-two naive, adult, male, Sprague-Dawley-descended rats, 9 to 10 weeks old, purchased from Charles River Breeding Laboratories (Wilmington, MA), served as subjects. The animals were assigned to one of six treatment groups $(n s=12$ ), which were counterbalanced for weight and baseline lick performance prior to
} 
differential treatment. All animals were individually housed in hanging wire-mesh cages in a vivarium that was maintained on a $16^{-h}$ light/8-h dark daily cycle. All manipulations occurred near the midpoint of the light portion of this cycle. Purina Lab Chow was freely available in the home cages. One week prior to the initiation of the study, all subjects were progressively deprived of water, and by Day 1 of the study were limited to $10 \mathrm{~min}$ per day of homecage access to water, provided approximately $23 \mathrm{~h}$ prior to any treatment scheduled for the following day. All subjects were handled thrice weekly for $30 \mathrm{sec}$ from arrival in the laboratory until the initiation of the study.

\section{Apparatus}

Three types of enclosures were used. Enclosure Clear was a clear, rectangular Plexiglas chamber measuring $22.75 \times 8.25 \times 13.00 \mathrm{~cm}$ $(1 \times w \times h)$. The floor was constructed of $0.48-\mathrm{cm}$-diameter rods, $1.91 \mathrm{~cm}$ center-to-center, connected by NE-2 neon bulbs, which allowed constant-current footshock to be delivered by means of a high voltage $\mathrm{AC}$ circuit in series with a 1.0-M $\Omega$ resistor. The output of the footshock generator could be passed through the neon bulbs to provide a $1.0-\mathrm{mA}, 0.5$-sec footshock through the grid floor of the enclosure. A block of wood, treated daily with six drops of methyl salicylate, provided a distinctive odor (i.e., wintergreen) in Enclosure Clear, which was housed inside an environmental isolation chest. Enclosure Clear was illuminated by a 7.5-W incandescent bulb. The bulb was mounted on an inside wall of the environmental isolation chest approximately $30 \mathrm{~cm}$ from the animal enclosure. Background noise in Enclosure Clear was a $70-\mathrm{dB}(\mathrm{C})$ (re. SPL) white noise produced by a speaker mounted on a wall. A second speaker was capable of delivering the CS, which consisted of either a $725-\mathrm{Hz}$ tone $12 \mathrm{~dB}(\mathrm{C})$ above background or a $3 / \mathrm{sec}$ click train $10 \mathrm{~dB}(C)$ above background. Enclosure Clear had a lick tube, left-right centered, protruding $3.5 \mathrm{~cm}$ from a narrow wall, $2.5 \mathrm{~cm}$ above the floor. The lick tube was attached to a lickometer circuit. There were six copies of Enclosure Clear.

Enclosure Black was a $30-\mathrm{cm}$-long box in a truncated- $V$ shape $(28 \mathrm{~cm}$ high and $21.50 \mathrm{~cm}$ wide at the top, which narrowed to $5.25 \mathrm{~cm}$ wide at the bottom). The short walls and roof were made of Plexiglas. The floor and 30-cm-long sides were constructed of sheet metal. The floor consisted of two 30-cm-long parallel metal plates, each $2 \mathrm{~cm}$ wide with a $1.25-\mathrm{cm}$ gap between them. A constant-current $1.0-\mathrm{mA}, 0.5-\mathrm{sec}$ footshock could be delivered through the walls and the floor of the enclosure. Background noise in Enclosure Black was a 70-dB(C) (re. SPL) complex humming sound produced by a speaker mounted on a wall. A second speaker was capable of delivering the same CSs as in Enclosure Clear. Enclosure Black was not illuminated. There was a lick tube in Enclosure Black, left-right centered, protruding $3.5 \mathrm{~cm}$ from a narrow wall, $1.5 \mathrm{~cm}$ above the floor, which was attached to a lickometer circuit. Each of six copies of Enclosure Black was housed in an individual environmental isolation chest.

Context Train was a $50 \times 8 \times 50 \mathrm{~cm}(1 \times w \times h)$ box with $0.64-\mathrm{cm}-$ diameter stainless steel grids, $1.59 \mathrm{~cm}$ center-to-center, that ran parallel to the long walls. The walls of Context Train were made of opaque Plexiglas and the ceiling was made of clear Plexiglas. The grids of the floor were connected with NE-2 neon bulbs, which permitted the administration of a 0.5 -sec, 1.0 -mA constant-current footshock. Unlike the other two enclosures, Context Train was not housed inside a separate environmental chest and no lick tube was present. The room containing Context Train was brightly illuminated by four overhead $40-\mathrm{W}$ fluorescent lights. The background noise level in Context Train was $60 \mathrm{~dB}(\mathrm{C})$ (re. SPL) provided primarily by the room's ventilation system. A ceiling-mounted speaker over Context Train was capable of delivering the same CSs as in the other two contexts. There were 12 copies of Context Train.

For half the subjects in each group, Enclosure Black served as Context Test and Enclosure Clear served as Context Irrelevant. For the other half of the subjects, these assignments were reversed. Experimental subjects received unsignaled footshocks in Context Test between CS training and the test sessions, whereas control subjects received equivalent unsignaled footshocks in Context Irrelevant. Context Train was the site of CS-US pairings for all subjects. All subjects were tested in Context Test.

\section{Procedure}

The procedure used in this study is summarized in Table 1.

Days 1-4 (context adaptation) served to acclimate the animals to the three contexts. On Days 1 and 3, all subjects were placed first in Context Train for $20 \mathrm{~min}$, then in Context Test for $1 \mathrm{~min}$, and finally in Context Irrelevant for $1 \mathrm{~min}$, Placements were separated by 1-h intervals in the home cage. The latter two placements were made brief in order to minimize possible latent inhibition to these contexts. Times to complete 50 licks were recorded in Contexts Test and Irrelevant. Sessions in these two enclosures were terminated after $1 \mathrm{~min}$ regardless of the number of licks emitted. Days 2 and 4 were identical to Days 1 and 3 except that the order

Table 1

Summary of Procedure

\begin{tabular}{|c|c|c|c|c|c|c|c|}
\hline \multirow[b]{2}{*}{ Day } & \multirow[b]{2}{*}{ Treatment } & \multicolumn{6}{|c|}{ Group } \\
\hline & & 0 & 5 & 30 & 300 & $0 \mathrm{C}$ & $300 \mathrm{C}$ \\
\hline $1-4$ & $\begin{array}{l}\text { Adapt to all } \\
\text { contexts }\end{array}$ & \multicolumn{6}{|c|}{ Adapt to all contexts } \\
\hline 5 & $\begin{array}{l}\text { Unsignaled } \\
\text { USs }\end{array}$ & $\begin{array}{l}\text { Test } \\
\text { Context }\end{array}$ & $\begin{array}{l}\text { Test } \\
\text { Context }\end{array}$ & $\begin{array}{l}\text { Test } \\
\text { Context }\end{array}$ & $\begin{array}{l}\text { Test } \\
\text { Context }\end{array}$ & $\begin{array}{l}\text { Context } \\
\text { Irrelevant }\end{array}$ & $\begin{array}{l}\text { Context } \\
\text { Irrelevant }\end{array}$ \\
\hline 6 & $\begin{array}{l}\text { Tone-US pairings } \\
\text { in Context Train }\end{array}$ & \multicolumn{6}{|c|}{ Tone-US pairings in Context Train } \\
\hline 7 & $\begin{array}{l}\text { Click-US pairings } \\
\text { in Context Train }\end{array}$ & \multicolumn{6}{|c|}{ Click-US pairings in Context Train } \\
\hline 8 & $\begin{array}{l}\text { Test tone in } \\
\text { Context Test }\end{array}$ & $\begin{array}{l}0-\sec \\
\text { tone-onset } \\
\text { delay }\end{array}$ & $\begin{array}{l}5 \text {-sec } \\
\text { tone-onset } \\
\text { delay }\end{array}$ & $\begin{array}{l}30-\sec \\
\text { tone-onset } \\
\text { delay }\end{array}$ & $\begin{array}{l}300-\sec \\
\text { tone-onset } \\
\text { delay }\end{array}$ & $\begin{array}{l}0 \text {-sec } \\
\text { tone-onset } \\
\text { delay }\end{array}$ & $\begin{array}{l}300-\text { sec } \\
\text { tone-onset } \\
\text { delay }\end{array}$ \\
\hline 9 & $\begin{array}{l}\text { Test clicks in } \\
\text { Context Test }\end{array}$ & $\begin{array}{l}0 \text {-sec } \\
\text { click-onset } \\
\text { delay }\end{array}$ & $\begin{array}{l}\text { 5-sec } \\
\text { click-onset } \\
\text { delay }\end{array}$ & $\begin{array}{l}30-\mathrm{sec} \\
\text { click-onset } \\
\text { delay }\end{array}$ & $\begin{array}{l}300 \text {-sec } \\
\text { click-onset } \\
\text { delay }\end{array}$ & $\begin{array}{l}0 \text {-sec } \\
\text { click-onset } \\
\text { delay }\end{array}$ & $\begin{array}{l}300 \text {-sec } \\
\text { click-onset } \\
\text { delay }\end{array}$ \\
\hline
\end{tabular}

Note-Subjects were reassigned to groups prior to Day 9 with new Groups $0,5,30$, and 300 counterbalanced for prior assignments to initial Groups $0,5,30$, and 300 , and with new Groups $0 \mathrm{C}$ and $300 \mathrm{C}$ counterbalanced for prior assignments to initial Groups $0 \mathrm{C}$ and $300 \mathrm{C}$. This minimized any possible effects of Test 1 upon Test 2 performance. 
of context exposure was Context Train, Context Irrelevant, and then Context Test. By Day 4, all animals completed 50 licks in Contexts Test and Irrelevant within the 1-min session.

On Day 5 (context-shock pairings), all subjects were placed in Context Test for a 14-min session. During this session, Groups 0 , 5,30 , and 300 received six pseudorandomly distributed, $0.5-\mathrm{sec}$, 1.0-mA unsignaled footshocks with a minimum separation of $1 \mathrm{~min}$. Two additional groups, Groups $0 \mathrm{C}$ and $300 \mathrm{C}$, received no footshocks. One hour later, all subjects were placed in Context Irrelevant for a 14-min session. During this session, Groups $0 \mathrm{C}$ and $300 \mathrm{C}$ received six pseudorandomly distributed, 0.5-sec, 1.0-mA shocks, whereas Groups $0,5,30$, and 300 received no shocks.

On Days 6 and 7 (CS-shock pairings), all subjects were placed in Context Train for $\mathbf{6 0}$ min. During this session, each animal received 12 presentations of an 18-sec CS, each immediately followed by a $0.5-\mathrm{sec}, 1.0-\mathrm{mA}$ footshock. These pairings were pseudorandomly distributed with a minimum intertrial interval of $3.0 \mathrm{~min}$. The CS was the tone on Day 6 and the click train on Day 7.

On Day 8 (Test 1), all subjects were placed in Context Test for $10 \mathrm{~min}$. The lick tube was absent at the start of the session. After $0 \mathrm{sec}$ for Groups 0 and $0 \mathrm{C}, 5 \mathrm{sec}$ for Group 5, $30 \mathrm{sec}$ for Group 30, and $300 \mathrm{sec}$ for Groups 300 and $300 \mathrm{C}$, the environmental chest was momentarily opened and the lick tube was inserted. For Groups 0 and $O C$, this consisted of initially closing the door of the chest and then immediately reopening it to insert the lick tube. Upon inserting the lick tube and closing the door of the environmental chest, the tone CS was presented for $5 \mathrm{~min}$. Times to complete the first 50 licks in the presence of the tone were recorded. At the end of the 5-min presentation, the tone was turned off and each subject remained in its test context until the end of the 10-min session, thereby equating across all groups exposure to both the tone (5 $\mathrm{min}$ ) and the test context $(10 \mathrm{~min})$. The delayed insertion of the lick tubes on the test trials served to equate deprivation levels at the moment of CS onset across animals assigned to different test conditions. In practice, each subject emitted 50 licks 8-12 sec after it began to drink, so time to complete $\mathbf{5 0}$ licks really reflects latency to begin drinking following tone onset. The 50-lick criterion merely prevented false, short latencies from animals that accidently brushed against the lick tube with their bodies prior to actual drinking.

On Day 9 (Test 2), the experimental subjects were reassigned to newly constituted Groups $0,5,30$, and 300 , with a quarter of the animals from each of the previous experimental groups being placed into each of these new experimental groups. Similarly, the control subjects were reassigned to newly constituted Groups $0 \mathrm{C}$ and $300 \mathrm{C}$, with half of the animals from each of the previous control groups being placed in each of these new control groups. Thus, the Day 9 groups were counterbalanced with respect to the Day 8 experience. Day 9 replicated the test procedure of Day 8, but with the click train rather than the tone as the CS. On both test days, subjects failing to complete 50 licks during the 5-min CS presentation were assigned a score of $5 \mathrm{~min}$. In practice, this maximum score was achieved on Day 8 by only 5 subjects: 2 in Group 0 , 2 in Group 5, and 1 in Group 30. On Day 9, no subject reached this maximum score. To improve the normality of the within-group distribution of scores, all durations were converted to log (base 10) time.

\section{RESULTS}

A one-way analysis of variance (ANOVA) on the Day 8 data revealed differences between groups $[F(5,66)=$ $6.26, p<.001]$ (see Figure 1). Planned comparisons revealed no difference between Groups $0 \mathrm{C}$ and $300 \mathrm{C}$ $(p>.25$ ), indicating that delay of CS onset in the absence of fear of the test context had no effect on suppres- sion to the tone. The relatively long durations to complete $\mathbf{5 0}$ licks by both of the control groups are indicative of fear of the tone as a result of its having been paired with footshock on Day $6 .{ }^{2}$ Group 0 was found to have suppressed more than Group $0 \mathrm{C}[F(1,66)=17.72, p<$ $.001]$, but no difference was seen between Groups 300 and $300 \mathrm{C}(p>.25)$. Thus, the response summation seen at $0 \mathrm{sec}$ was not evident $300 \mathrm{sec}$ later. A monotonic tendency toward less suppression to the tone with increasing delays of CS onset was evident in the four groups that had received unsignaled footshock in Context Test. Both Group 0 and Group 5 exhibited more suppression than did Group $300[F \mathrm{~s}(1,66) \geq 6.93$, ps $<.025]$, and Group 0 differed from Group $30[F(1,66)=4.88$, $p<.05]$.

Greater lick suppression to the tone on Day 8 by Group 0 than by Group $0 \mathrm{C}$ indicates that response summation of the tone with the test context occurred with a 0 -sec delay of CS onset at test, and the similarity in suppression by Groups 300 and $300 \mathrm{C}$ suggests that response summation did not occur with a 300-sec delay. However, even at $300 \mathrm{sec}$, there was a tendency, albeit nonsignificant, toward response summation; that is, Group 300 tended to suppress more than Group $300 \mathrm{C}$ (see Figure 1). To determine whether the response summation of the CS and test context was greater at $0 \mathrm{sec}$ into the test session than at $300 \mathrm{sec}$ into the session, a $2 \times 2$ ANOVA was performed on Groups $0,0 \mathrm{C}, 300$, and 300C. An interaction of location of unsignaled shock and delay of shock onset at test on Day 8 was found $[F(1,44)=5.12, p<.05]$, which is consistent with response summation of the tone

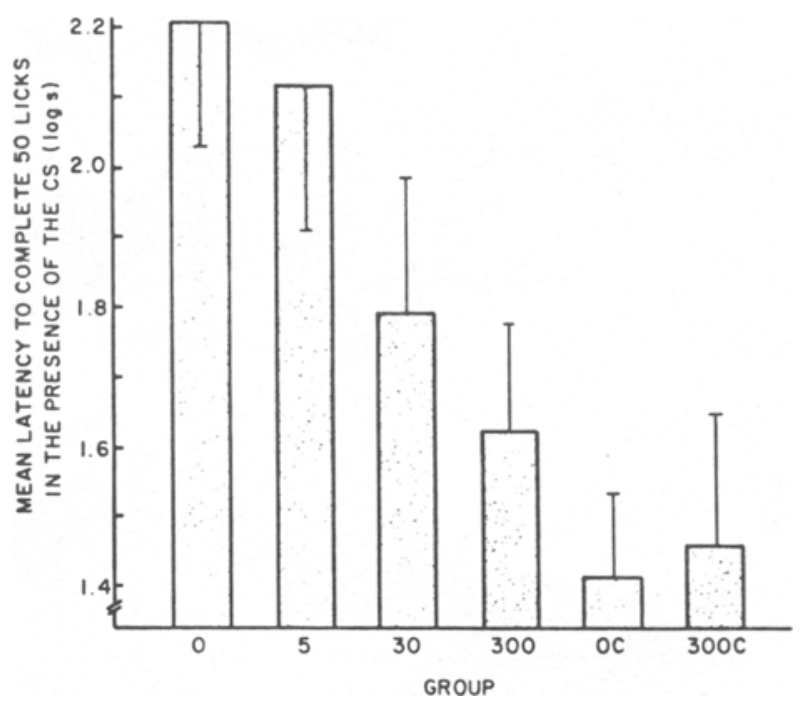

Figure 1. Mean latencies to complete 50 licks in the presence of the tone on Day 8. All groups received identical tone-shock pairings in Context Train. In addition, Groups 0, 5, 30, and 300 received unsignaled shocks in Context Test, whereas Groups OC and 300C received comparable shocks in Context Irrelevant. The numbers in the group desigmation denote the delay of tone onset after the initiation of the test session. Brackets denote standard errors. 
and test context being greater with a 0-sec delay of CS onset at test than with a 300-sec delay of CS onset.

A one-way ANOVA on Day 9 lick suppression in response to the click train also showed significant differences between groups $[F(5,66)=2.38, p<.05]$ (see Figure 2). Planned comparisons revealed no difference between Groups $0 \mathrm{C}$ and $300 \mathrm{C}(p>.25)$, indicating that, as on Day 8, delay of CS onset had no effect upon lick suppression by subjects for which the test context had not been paired with shock. However, both control groups exhibited suppression to the clicks (i.e., both means were well above the 1.02-log sec mean seen when the CS had not been paired with footshock in a similar experiment; see Note 2). This indicates that the click-shock pairings of Day 7 had transformed the clicks into a conditioned excitor. As with the tone, Group 0 was found to have suppressed more to the clicks than did Group $0 C[F(1,66)$ $=6.56, p<.025]$, suggesting that there had been partial recovery by Day 9 from the 10 min of test-context extinction on Day 8 that had been sufficient to reduce context fear on Day 8 to the point that the animals would drink. However, a comparison of Groups 300 and $300 \mathrm{C}$ revealed no differences $(p>.25)$. As with the tone test on Day 8, a monotonic tendency toward decreased suppression with increasing delays of CS onset was seen in the four groups that had received unsignaled footshock in the test context. Group 0 suppressed more than Group $300[F(1,66)=5.06, p<.05]$, but no other difference among the groups that had received unsignaled shock in Context Test was detected (all $p s>.25$ ). A $2 \times 2$ ANOVA of the Day 9 scores from Groups $0,300,0 \mathrm{C}$, and $300 \mathrm{C}$ yielded only a nonsignificant tendency toward

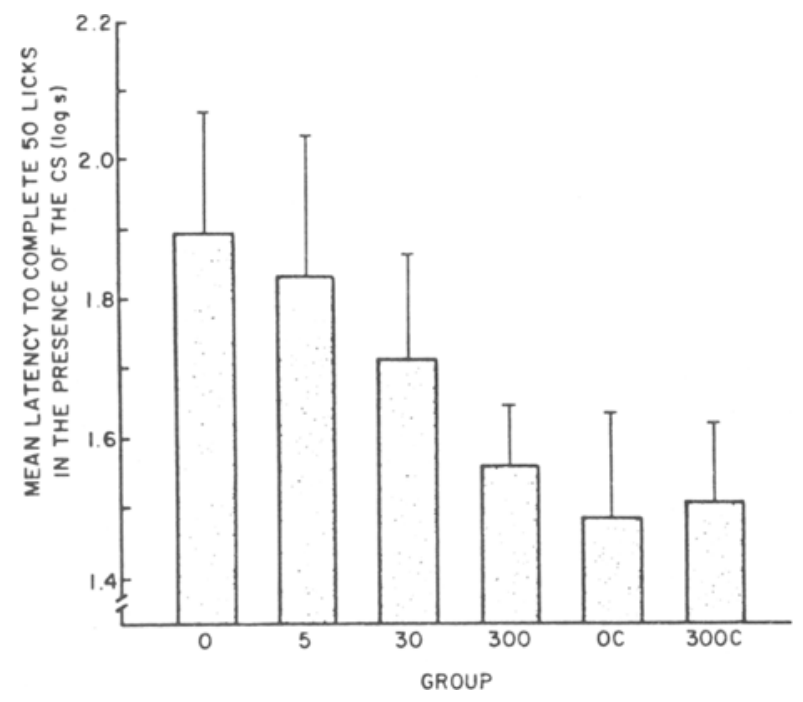

Figure 2. Mean latencies to complete $\mathbf{5 0}$ licks in the presence of the click train on Day 9. All groups received identical click-shock pairings in Context Train. In addition, Groups 0, 5, 30, and 300 received unsignaled shocks in Context Test, whereas Groups $0 \mathrm{C}$ and 300C received comparable shocks in Context Irrelevant. The numbers in the group designation denote the delay of click onset after the initiation of the test session. Brackets denote standard errors. an interaction of unsignaled shock administration and delay of CS onset $[F(1,44)=2.85, .10>p>.05]$.

\section{DISCUSSION}

Administration of unsignaled footshock in Context Irrelevant on Day 5 to the control subjects (Groups $0 \mathrm{C}$ and $300 \mathrm{C}$ ) comparable to that received by the experimental subjects in Context Text on the same day precludes the possibility that diffuse fear not associated with Context Test produced the observed difference between Group 0 and Group $0 \mathrm{C}$. Consequently, summation of conditioned suppression elicited by the CS with conditioned suppression elicited by the test context was likely the source of the greater suppression seen in Group 0 than in Group $0 \mathrm{C}$. The Day 8 and Day 9 test scores both decreased monotonically with increasing delay of CS onset on the test trial. Presumably, this reflects a decreasing contribution to lick suppression in the presence of the CS by the test contextfootshock association.

We cannot be certain of the basis for the decrease in lick suppression as the delay of CS onset was increased. However, extinction of the test context-footshock association prior to CS onset is one distinct possibility, and a waning of attention to the context as the test session progressed is another possibility. A comparison of the Day 9 data for the clicks with the Day 8 data for the tone indicates that the $10 \mathrm{~min}$ of test-context exposure on Day 8 decreased lick suppression on Day 9 in all of the experimental groups (i.e., Groups $0,5,30$, and 300 ) relative to the control groups, presumably due to partial extinction of, or long-term habituation to, the test context on Day 8. Indirect support for the extinction interpretation of the present results comes from the observation that occasion setting by a context does not appear to wane when there are long intervals between initiation of the test session and onset of the nominal CS (e.g., Bouton \& Swartzentruber, 1986). If attention to the context waned during a test session, both the excitatory role and the occasion-setting role of the context might be expected to wane as time into the test session increased.

Wagner's (1981) SOP model offers an alternative to both extinction of, and habituation to, the context as an explanation of the present data. Specifically, SOP predicts that each placement in the test context causes the representation of the test context to move from the Inactive state (I), which has no impact on behavior, to the Primary Active state (A1), which strongly influences behavior. With the passage of time after entering $A 1$, representations are presumed to decay from $\mathrm{A} 1$, first into the Secondary Active state (A2), which weakly influences behavior, and then into the I state. Consequently, with delayed CS onset, more of the test-context representation should be in $A 2$, as opposed to $A 1$, than would be the case with immediate onset of the CS at the beginning of the test session. As A2 is assumed to influence responding less than does $\mathrm{Al}$, the contribution of the test context to response summation should diminish as the time between the initi- 
ation of the test session and CS onset is increased. Moreover, SOP correctly predicts that spontaneous recovery of the response potential of the test context will be seen at the beginning of the Day 9 test session because the representation of the test context will have decayed overnight into State I and hence will be available at the beginning of the Day 9 test session for reactivation back into Al.

Other than the apparent reduction in context fear among the experimental groups, the Day 9 results are highly similar to the Day 8 results. The appearance of a monotonic gradient of response summation on the second test day despite the reassignment of the animals to groups (see Procedure section) indicates that the gradient observed on the first test day was not an artifact of extraexperimental subject differences.

Our conclusion, that response summation of CSs and excitatory test contexts is greater with CS onset early in the test session than later in the test session, does not speak to the degree that the compound test stimulus (i.e., CS and excitatory context) elicits suppression greater than that elicited by the CS or context alone. Comparison of Groups 0 and $0 \mathrm{C}$ clearly indicates that with immediate tone onset, the compound of the CS and the excitatory context was a more effective stimulus than was the tone alone. But the experiment did not include a control group that was tested in the excitatory context in the absence of a punctate CS. On the basis of the current data, we can only conclude that the excitatory context augmented suppression to the tone, not that the tone augmented suppression to the context. In other words, we cannot speak to the degree that the present summation was algebraic, with linear addition of fear; however, without a response rule to map fear into suppression, the mathematical expression of the summation process could not be surmised even with this additional control group.

The finding that CSs and contexts tend to summate most readily when they have a common onset during the test trial parallels the need for two CSs to have a common onset in order to obtain maximal response summation of the CSs. That is, to the extent that two CSs each separately elicit conditioned responses, a summated conditioned response to the two CSs presented in compound is most apt to be seen if the CSs are initiated such that the two component conditioned responses occur at the same time (Grings, 1972; Weiss, 1972). Other than instances in which extensive training with long CSs has resulted in inhibition of delay developing to early parts of the individual CSs, conditioned responses ordinarily occur momentarily after CS onset. Thus, our data stand as an instance of the context's influencing acquired behavior in a manner highly similar to that of a punctate CS.

The results of the present experiment indicate that onset of the CS very early in the test session can be an important factor in obtaining response summation of a CS and its test context. With 0-, 5-, and 30-sec delays of CS onset on Day 8, response summation was observed. With 300-sec delay of CS onset, the summation effect was not significant; however, there was still a weak tendency toward response summation of the tone and the context. Despite this lack of significance, the hint of a residual tendency in conjunction with the monotonic gradient provided by the groups with shorter delays suggests that, with appropriate parameters, response summation might be obtainable even with a test-trial delay of CS onset of $300 \mathrm{sec}$. For example, a context-summation test with a less excitatory CS might prove more sensitive than the current summation test, thereby yielding appreciable response summation with delays of CS onset at testing of $300 \mathrm{sec}$ and more. However, all other factors being equal, such delays can be expected to decrease the likelihood of observing response summation of a CS and its test context. Extinction of the test context prior to CS onset is a likely basis for this effect, and the results of the present experiment suggest that such context extinction is subject to partial spontaneous recovery over $24 \mathrm{~h}$.

Differences in delay of CS onset likely contributed to the discrepancy in prior reports concerning response summation of CSs and their test contexts. Awareness of the influence of delayed CS onset during testing on response summation is potentially important in the design of future studies that either want or do not want to obtain response summation. In the latter category are studies in which response summation would be a confound, for example research on occasion setting by the test context.

\section{REFERENCES}

Balaz, M. A., Capra, S., Hartl, P., Miller, R. R. (1981). Contextual potentiation of acquired behavior after devaluing direct contextUS associations. Learning \& Motivation, 12, 383-397.

Balaz, M. A., Capra, S., Kasprow, W. J., \& Miller, R. R. (1982). Latent inhibition of the conditioning context: Further evidence of contextual potentiation of retrieval in the absence of appreciable context-US associations. Animal Leaming \& Behavior, 10, 242-248.

Bouton, M. E., \& KING, D. A. (1986). Effect of context on performance to conditioned stimuli with mixed histories of reinforcement and nonreinforcement. Journal of Experimental Psychology: Animal Behavior Processes, 12, 4-15.

Bouton, M. E., \& Swartzentruber, D. (1986). Analysis of the associative and occasion-setting properties of contexts participating in a Pavlovian discrimination. Joumal of Experimental Psychology: Animal Behavior Processes, 12, 333-350.

GrINGs, W. W. (1972). Compound stimulus transfer in human classical conditioning. In A. H. Black \& W. F. Prokasy (Eds.), Classical conditioning: Vol. 2. Current research and theory (pp. 248-266). New York: Appleton-Century-Crofts.

Miller, R. R., MATZel, L. D. (1988). The comparator hypothesis: A response rule for the expression of associations. In G. H. Bower (Ed.), The psychology of learning and motivation (Vol. 22, pp. 5192). Oriando, FL: Academic Press.

WAGNER, A. R. (1981). SOP: A model of automatic memory processing in animal behavior. In N. E. Spear \& R. R. Miller (Eds.), Information processing in animals: Memory mechanisms (pp. 5-47). Hillsdale, NJ: Erlbaum.

WEISS, S. J. (1972). Stimulus compounding in free-operant and classical conditioning: A review and analysis. Psychological Bulletin, 78, 189-208. 


\section{NOTES}

1. The potential of a test context to yield response summation with a CS should not be confused with the potential of the test context to act as an occasion setter for the CS under appropriate circumstances (e.g., Bouton \& King, 1986). Moreover, neither response summation with the test context nor occasion setting by the test context should be confused with the modulatory role a CS's training context can have on responding to a CS (e.g., Miller \& Matzel, 1988). Even when training and test context are the same, these three roles of context appear to be independent in action and summative in behavioral consequence.

2. The present experiment lacked control groups in which the tone was not reinforced with footshock. However, we conducted a two-group study at about the same time as the present experiment. These two groups were treated identically to Group $0 \mathrm{C}$ and Group 0 in the present experiment except that training and testing with the clicks was omitted and the tone was not reinforced on the tone-training day. When the un- signaled shocks had been delivered in Context Irrelevant, mean time ( \pm standard error) to complete 50 licks in the presence of the nonreinforced tone in Context Test was $1.02( \pm .08) \log \mathrm{sec}$. When the unsignaled shocks had been delivered in Context Test, mean time ( \pm standard error) to complete 50 licks in the presence of the nonreinforced tone in Context Test was $1.49( \pm .19) \log \mathrm{sec}$. These two groups differed significantly $[t(10)=2.28, p<.05]$, indicative of fear of the context in which unsignaled shock had been administered. Thus, with apologies for between-experiments comparisons, 0 -sec delay of tone onset in Context Test yielded a mean of $2.21 \mathrm{log} \mathrm{sec}$ when both the tone and Context Test had been paired with shock (Group 0), $1.42 \mathrm{log} \mathrm{sec}$ when only the tone had been paired with shock (Group 0C), $1.49 \log \mathrm{sec}$ when only Context Test had been paired with shock, and $1.02 \mathrm{log} \mathrm{sec}$ when neither the tone nor Context Test had been paired with shock.

(Manuscript received August 25, 1988; revision accepted for publication April 17, 1989.) 